\title{
Development of Repair Techniques for Cast Iron Engine Blocks by Additive Manufacturing
}

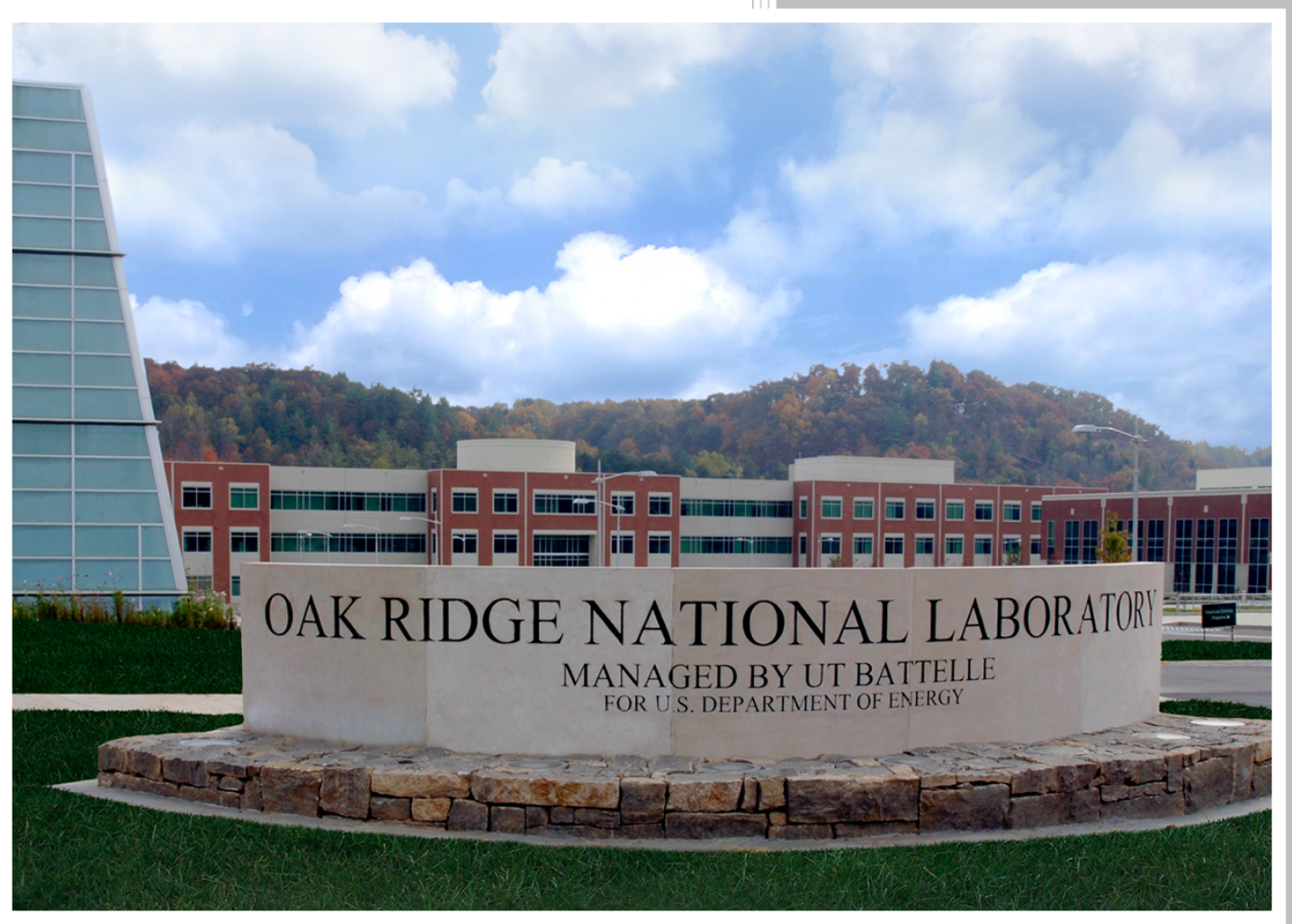

Niyanth Sridharan

June 3, 2020

CRADA FINAL REPORT NFE-16-06053

Approved for Public Release. Distribution is Unlimited. 


\title{
DOCUMENT AVAILABILITY
}

Reports produced after January 1, 1996, are generally available free via US Department of Energy (DOE) SciTech Connect.

Website www.osti.gov

Reports produced before January 1, 1996, may be purchased by members of the public from the following source:

\author{
National Technical Information Service \\ 5285 Port Royal Road \\ Springfield, VA 22161 \\ Telephone 703-605-6000 (1-800-553-6847) \\ TDD 703-487-4639 \\ Fax 703-605-6900 \\ E-mail info@ntis.gov \\ Website http://classic.ntis.gov/
}

Reports are available to DOE employees, DOE contractors, Energy Technology Data Exchange representatives, and International Nuclear Information System representatives from the following source:

Office of Scientific and Technical Information

PO Box 62

Oak Ridge, TN 37831

Telephone 865-576-8401

Fax 865-576-5728

E-mail reports@osti.gov

Website http://www.osti.gov/contact.html

\begin{abstract}
This report was prepared as an account of work sponsored by an agency of the United States Government. Neither the United States Government nor any agency thereof, nor any of their employees, makes any warranty, express or implied, or assumes any legal liability or responsibility for the accuracy, completeness, or usefulness of any information, apparatus, product, or process disclosed, or represents that its use would not infringe privately owned rights. Reference herein to any specific commercial product, process, or service by trade name, trademark, manufacturer, or otherwise, does not necessarily constitute or imply its endorsement, recommendation, or favoring by the United States Government or any agency thereof. The views and opinions of authors expressed herein do not necessarily state or reflect those of the United States Government or any agency thereof.
\end{abstract}


ORNL/TM-2016/713

CRADA/NFE-16-06108

Materials Science and Technology Division Advanced Manufacturing Office

Development of Volume Deposition on Cast Iron by Additive Manufacturing

\author{
Authors \\ Niyanth Sridharan \\ Ryan. R. Dehoff \\ Brian. H. Jordan \\ S. S. Babu \\ Date Published: \\ June 3, 2020 \\ Prepared by \\ OAK RIDGE NATIONAL LABORATORY \\ Oak Ridge, Tennessee 37831-6283 \\ managed by \\ UT-BATTELLE, LLC \\ for the \\ US DEPARTMENT OF ENERGY \\ under contract DE-AC05-00OR22725
}

Approved For Public Release 



\section{CONTENTS}

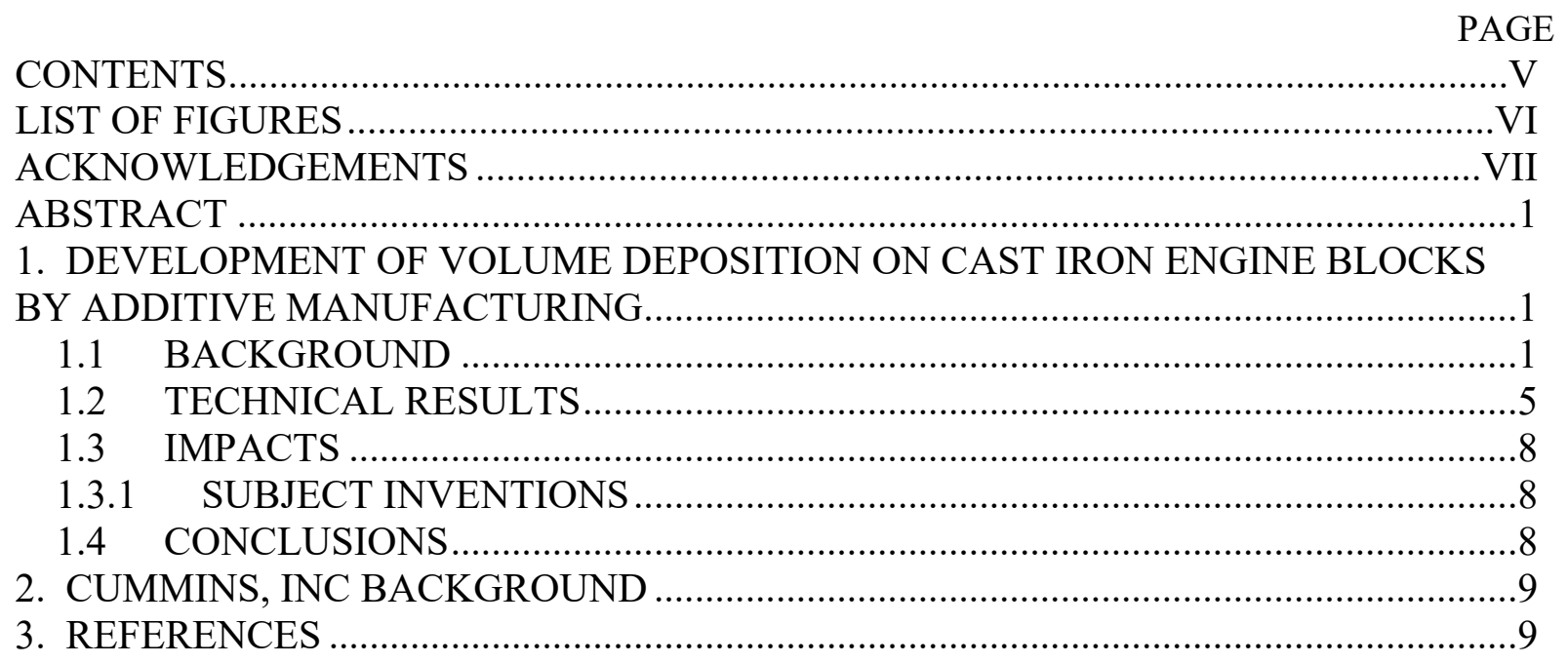




\section{LIST OF FIGURES}

Figure 1. CALPHAD calculations showing the phase equilibria for various compositions showing the mole fractions of BCC and FCC phases as a function of temperature.................3 Figure 2. Showing various scan strategies used and the associated cracking tendencies in the fabricated samples.

Figure 3. Optical micrographs of the uni-direction raster (a) Montage showing the presence of cracking in the cast iron substrate (b) Cracking at the edges shown at higher magnification

(c) Cracking in the center shown at a higher magnification...

Figure 4. X-Ray diffraction results of the (a) Powder (b) Bi directional raster (c) Uni directional raster (d) 45 degree raster. The X-Ray diffraction patterns shown the presence of $100 \%$ FCC phase in the builds.

Figure 5. Optical micrograph (a) Un etched micrograph of the $40 \mathrm{X} 40 \mathrm{X} 40 \mathrm{~mm} 3 \mathrm{samples}$ showing cracks at the edges (b) 20X20X20 mm33 sample fabricated with identical process parameters (c) Etched microstructure of (a) (d) Interface at higher magnification (e) Micrograph of the deposit showing a martensitic structure.....

Figure 6. X-Ray diffraction of the powder and the build showing the presence of residual austenite films in the samples

Figure 7. Optical micrographs of the (a) 40X40X40 $\mathrm{mm}^{3}$ sample in the un etched condition. Note that the cracks are smaller compared to the previous study (b) 20 X20X20 $\mathrm{mm}^{3}$ sample in the un etched condition clearly showing the absence of cracking at the interface (kindly refer to figure 5 (b) ). (c) and (d) Etched micrographs of the samples showing the presence of martensite in the matrix with retained austenite in the inter dendritic area which is higher in alloying content

Figure 8. X-Ray diffraction the build showing the presence of residual austenite films in the samples 


\section{ACKNOWLEDGEMENTS}

This CRADA NFE-16-06053 was conducted as a Technical Collaboration project within the Oak Ridge National Laboratory (ORNL) Manufacturing Demonstration Facility (MDF) sponsored by the US Department of Energy Advanced Manufacturing Office (CPS Agreement Number 24761).

Opportunities for MDF technical collaborations are listed in the announcement "Manufacturing Demonstration Facility Technology Collaborations for US Manufacturers in Advanced

Manufacturing and Materials Technologies" posted at http:/web.ornl.gov/sci/manufacturing/docs/FBO-ORNL-MDF-2013-2.pdf. The goal of technical collaborations is to engage industry partners to participate in short-term, collaborative projects within the Manufacturing Demonstration Facility (MDF) to assess applicability and of new energy efficient manufacturing technologies. Research sponsored by the U.S. Department of Energy, Office of Energy Efficiency and Renewable Energy, Advanced Manufacturing Office, under contract DE-AC0500OR22725 with UT-Battelle, LLC. 


\begin{abstract}
ORNL partnered with Cummins Inc to demonstrate the feasibility of using additive manufacturing techniques to deposit large volume of new material on cast iron in the context of remanufacturing. Remanufacturing at Cummins Inc is carried out to repair any field damage and, in some cases, provide additional value by adding new features. Large volume deposition on difficult to weld materials is a challenging problem due to involved metallurgy. Phase- 1 of this work evaluated the feasibility of using laser directed energy deposition technique to deposit new material layer by layer on cast iron engine blocks. During phase-1 deposits were made using Inconel-718, Nickel, Nr-Cr-B braze filler. Leveraging the knowledge gained during Phase-1, Phase-2 focused on developing a lowcost crack resistant ferrous alloy to repair cast iron via volume deposition techniques without preheating. Three different alloy chemistries were identified, and trials were performed on cast iron substrates to identify the optimal chemistry that provided adequate resistance to cracking in both, the deposits as well as the cast iron substrate.
\end{abstract}

\title{
1. DEVELOPMENT OF VOLUME DEPOSITION ON CAST IRON ENGINE BLOCKS BY ADDITIVE MANUFACTURING
}

This Phase 2 technical collaboration project (MDF-TC-2016-037) was begun on November 9, 2017. Phase 2 identified two compositions that can be deposited via laser directed energy deposition process on cast iron while mitigating cracking, under certain geometric constraints. This could lead to significant cost savings, ability to add new features and reduced emissions. The findings need to be validated by depositing the developed material in a representative geometry.

\subsection{BACKGROUND}

Cummins Inc aims to remanufacture engine blocks by being able to add large volume of material on existing cast iron to repair various service damage and add new features. Initial research in Phase1 of this collaboration showed the presence of cracks in the heat affected zone of the cast iron. Detailed tests and microstructure investigations showed that the cracking occurred due the formation of tensile residual stresses in the heat affected zone due to the differences in the co-efficient of thermal expansion between the substrate $\left(13-15^{\circ} \mathrm{C}-1\right)$ and deposits $\left(11.5^{\circ} \mathrm{C}-1\right)$.

Cast iron by virtue of its high carbon content is a difficult to weld material $[1,2]$. Traditionally cast iron has been welded using high nickel containing fillers to stabilize austenite in the heat-affected zone to prevent cracking [3-6]. In addition, high Ni containing alloys are also soft and hence are capable of absorbing the shrinkage stresses [6]. However, Ni rich alloys in addition to a being soft have a significant difference in CTE compared to cast iron.

\subsection{TECHNICAL RESULTS}

A detailed review of the literature was performed to identify ferrous materials (Table-1) that would potentially minimize the residual stresses accumulated in the build. It has previously been reported that by effectively leveraging the martensitic transformation in the steels the tensile residual stresses from solidification can be effectively countermanded and a compressive residual stress can be induced in the zones adjacent to the weld metal. Typically, in steels martensitic transformation occurs around $400-500{ }^{\circ} \mathrm{C}$ depending on the alloying elements and the carbon concentration. However, in 
some special consumables the martensitic transformation occurs between $150-200{ }^{\circ} \mathrm{C}$. Since the thermal expansion of austenite is larger than that of ferrite the volume expansion is maximized at lower temperatures. Ferrite has higher yield strength than austenite (at low temperature) and hence there is a lesser compensation of contraction strain by plastic relaxation. When transformation occurs at low temperatures there is a greater accumulation of stress before the low transformation temperature is reached. This leads to a greater bias in the microstructure in constrained specimens, making the shear strain more effective in counteracting thermal contraction strains.

Therefore, this approach was used to develop and design the consumable which has a low martensitic transformation temperature (LTT) and also limit the carbon equivalent in the steel to ensure resistance to hydrogen induced cracking. An extensive literature survey was conducted to identify the LTT alloys that have been previously used and the alloys along with their martensite start temperatures are summarized in Table 1. In addition, it has also been shown in previous results that better resistance to cold cracking was obtained by optimizing the amount the retained austenite in the builds. Studies have also shown that low transformation temperature (LTT) materials with a low C, high $\mathrm{Cr}$ and $\mathrm{Ni}$ are more resistant to cracking and have a high toughness as well. Therefore 5 compositions were down selected to develop filler materials for the repair of cast iron blocks. The compositions used in this work are shown in Table 2.

Table 1. Showing the different LLT alloys that have been used and the associated martensite start temperatures

\begin{tabular}{|c|c|c|c|c|c|c|c|}
\hline & \multirow[b]{2}{*}{$\mathrm{C}$} & \multirow[b]{2}{*}{$\mathrm{Mn}$} & \multirow[b]{2}{*}{$\mathrm{Cr}$} & \multirow[b]{2}{*}{$\mathrm{Ni}$} & \multicolumn{3}{|c|}{ Ms temperature ${ }^{\circ} \mathrm{C}$} \\
\hline & & & & & $\begin{array}{c}\text { Payson \& } \\
\text { savage }\end{array}$ & $\begin{array}{c}\text { Grange \& } \\
\text { Stewart }\end{array}$ & $\begin{array}{c}\text { Steven \& } \\
\text { Haynes }\end{array}$ \\
\hline Alloy 1 & 0.089 & 1.26 & 5.7 & 5.3 & 181.8857 & 132.307 & 289.856 \\
\hline Alloy 2 & 0.07 & 0.72 & 0.69 & 8.2 & 296.733 & 298.801 & 352.714 \\
\hline Alloy 3 & 0.066 & 1.29 & 10 & 5 & 73.6408 & -22.007 & 231.759 \\
\hline Alloy 4 & 0.037 & 1.29 & 11.9 & 5.6 & 19.9851 & -97.088 & 203.005 \\
\hline Alloy 5 & 0.025 & 0.7 & 10 & 10 & 22.7725 & -81.255 & 185.84 \\
\hline Alloy 6 & 0.01 & 1.8 & 12.5 & 6.7 & -23.497 & -151.86 & 169.92 \\
\hline Alloy 7 & 0.02 & 0.19 & 9.76 & 10.14 & 45.673 & -52.991 & 206.893 \\
\hline Alloy 8 & 0.076 & 0.55 & 6.14 & 6.13 & 183.5528 & 131.401 & 298.071 \\
\hline Alloy 9 & 0.04 & 0.7 & 8 & 6 & 140.422 & 68.73 & 280.73 \\
\hline Alloy 10 & 0.04 & 0.7 & 10 & 8 & 51.422 & -47.87 & 212.73 \\
\hline Alloy 11 & 0.04 & 0.7 & 10 & 10 & 18.022 & -86.67 & 178.73 \\
\hline Alloy 12 & 0.04 & 0.7 & 10 & 12 & -15.378 & -125.47 & 144.73 \\
\hline Alloy 13 & 0.04 & 0.7 & 8 & 8 & 107.022 & 29.93 & 246.73 \\
\hline Alloy 14 & 0.04 & 0.7 & 10 & 10 & 18.022 & -86.67 & 178.73 \\
\hline Alloy 15 & 0.03 & 0.7 & 10 & 10 & 21.189 & -83.06 & 183.47 \\
\hline Alloy 16 & 0 & 0.2 & 11 & 3.41 & 129.593 & 36.166 & 309.37 \\
\hline Alloy 17 & 0 & 0.28 & 12 & 9.99 & -10.757 & -133.498 & 177.846 \\
\hline
\end{tabular}

The CALPHAD calculations along with martensite start temperatures were performed on the alloys shown in Table 2. Carbon equivalent for all the compositions were also calculated and the alloys were ranked based on the susceptibility to hydrogen induced cracking. The CALPHAD results are also presented in Figure 1. CALPHAD was performed to understand the phase fractions, in particular the residual amount of retained austenite that could be expected in the builds. Ideally it has been shown that an $8-10 \%$ volume fraction austenite improves resistance to cracking.

Table 2. Shows the different LLT alloys down selected and their corresponding martensite start 
temperatures and carbon equivalents.

\begin{tabular}{|l|l|l|l|l|l|l|l|}
\hline Composition & $\mathrm{C}(\mathrm{wt} \%)$ & $\mathrm{Cr}(\mathrm{wt} \%)$ & $\mathrm{Ni}(\mathrm{Wt} \%)$ & $\begin{array}{l}\text { Payson and } \\
\text { Savage }\end{array}$ & $\begin{array}{l}\text { Grange and } \\
\text { Stewart }\end{array}$ & $\begin{array}{l}\text { Steven and } \\
\text { Haynes }\end{array}$ & $\begin{array}{l}\text { Carbon } \\
\text { Equivalent }\end{array}$ \\
\hline Composition 1 & 0.01 & 11.25 & 10.64 & -22.7412 & -141.7218 & 141.995 & 3.06 \\
\hline Composition 2 & 0.083 & 9.375 & 10.20 & 41.949 & -54.3015 & 189.1625 & 2.64 \\
\hline Composition 3 & 0.077 & 8.75 & 10.05 & 63.5124 & -25.1614 & 204.885 & 2.5 \\
\hline Composition 4 & 0.055 & 6.25 & 9.47 & 149.766 & 91.399 & 267.775 & 1.9 \\
\hline Composition 5 & 0.044 & 5 & 9.172 & 192.8928 & 149.6792 & 299.22 & 1.66 \\
\hline Composition 6 & 0.039 & 4.375 & 9.03 & 214.4562 & 178.8193 & 314.9425 & 1.52 \\
\hline Composition 7 & 0 & 0 & 8 & 365.4 & 382.8 & 425 & 0.53 \\
\hline Composition 8 & 0.11 & 12.5 & 10.93 & -65.868 & -200.002 & 110.55 & Austenite \\
\hline
\end{tabular}
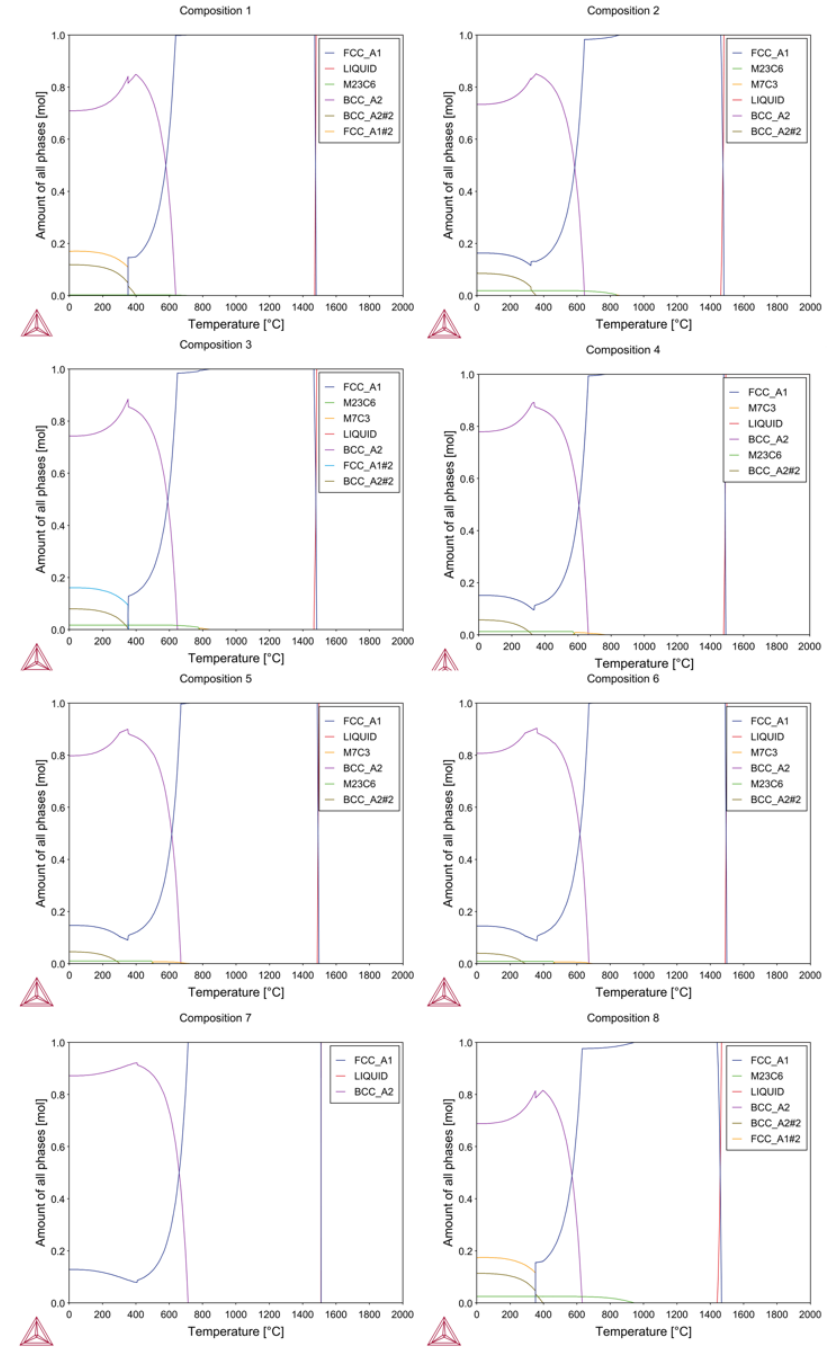

Figure 1. CALPHAD calculations showing the phase equilibria for various compositions showing the mole fractions of BCC and FCC phases as a function of temperature. 
Based on the CALPHAD results on phase fractions (Figure 1) and the calculations of Ms temperatures three compositions were down selected for trails. The compositions are

1) Composition 8

2) Composition 7

3) Composition 3

The trials were performed on cast iron substrates using laser blown powder deposition process. The results are summarized as follows.

\section{Deposits fabricated with Composition-8:}

Composition 8 was completely austenitic and served as a baseline to evaluate the benefits of using LTT materials. Three different deposit scan strategies were evaluated to understand the differences in cracking behavior. The scan strategies used and the builds are shown in Figure 2. All the builds had varying degrees of cracking at the deposit/substrate interface.

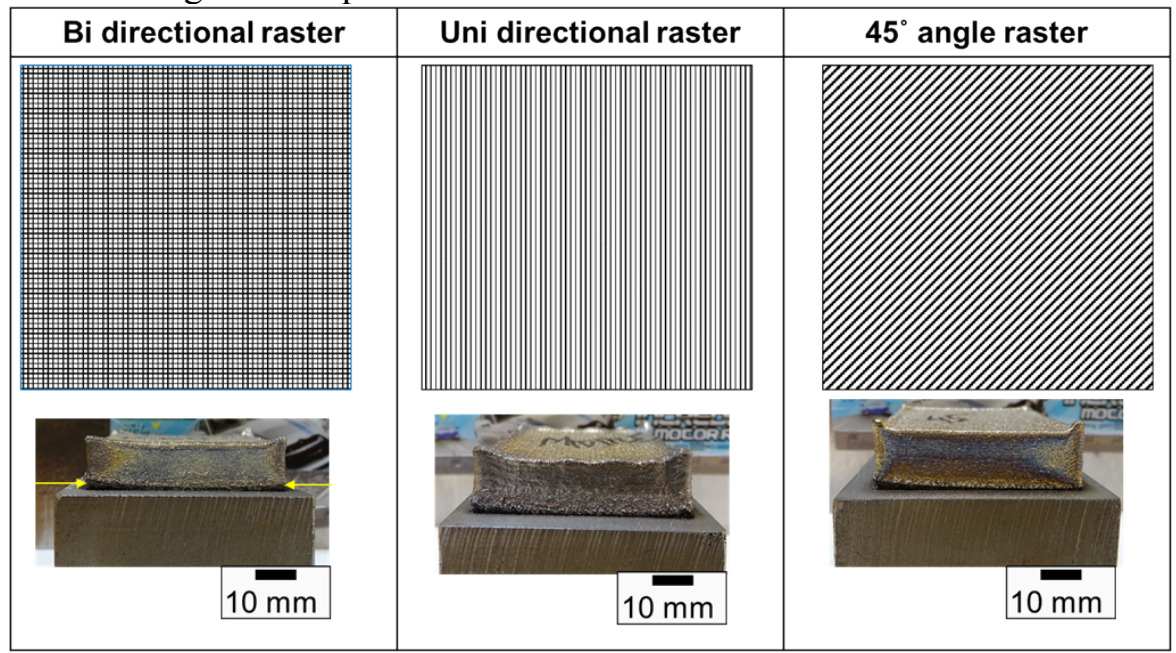

Figure 2. Showing various scan strategies used and the associated cracking tendencies in the fabricated samples.

To further understand the reasons for cracking, detailed microscopy analysis was performed on the samples. The microscopy results are shown in Figure 3. The micrographs show that the crack originates in the cast iron heat affected zone and are more pronounced at the edges and significantly and are limited in the center. In addition, the primary austenitic structure also leads to severe cracking in the first few passes in the weld metal. This lack of phase transformation could have accelerated the cracking due to the shrinkage stresses. X-Ray diffraction analysis was performed on the powder and the builds. The data clearly shows the absence of any phase transformation from the austenitic phase to the martensitic phase. The results of the X-Ray diffraction are presented in Figure 4. 

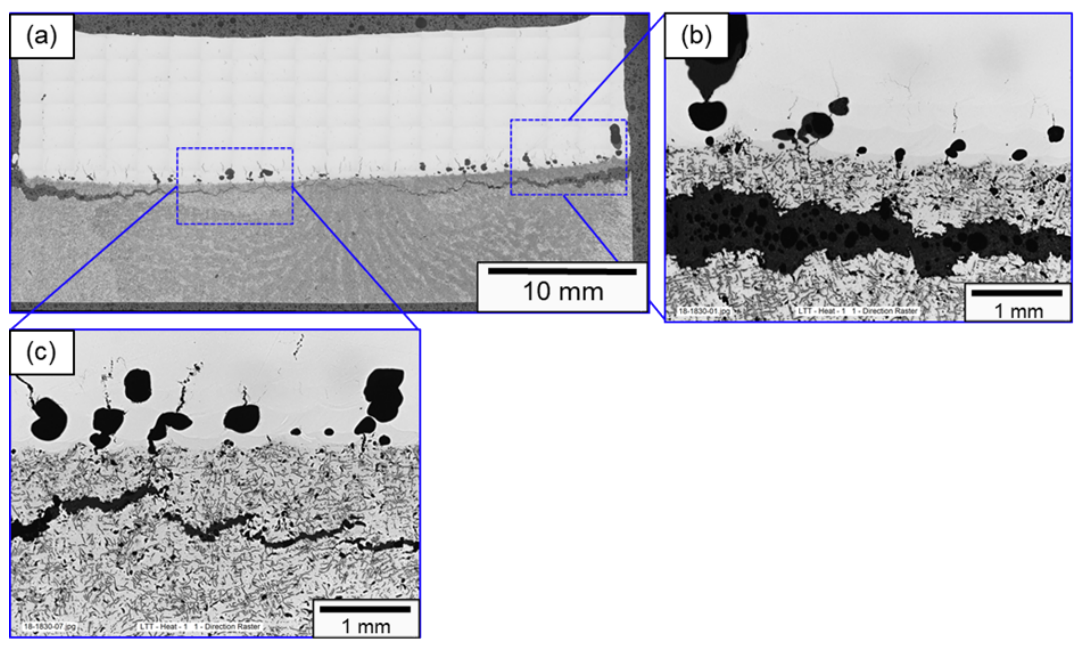

Figure 3. Optical micrographs of the uni-direction raster (a) Montage showing the presence of cracking in the cast iron substrate (b) Cracking at the edges shown at higher magnification (c) Cracking in the center shown at a higher magnification
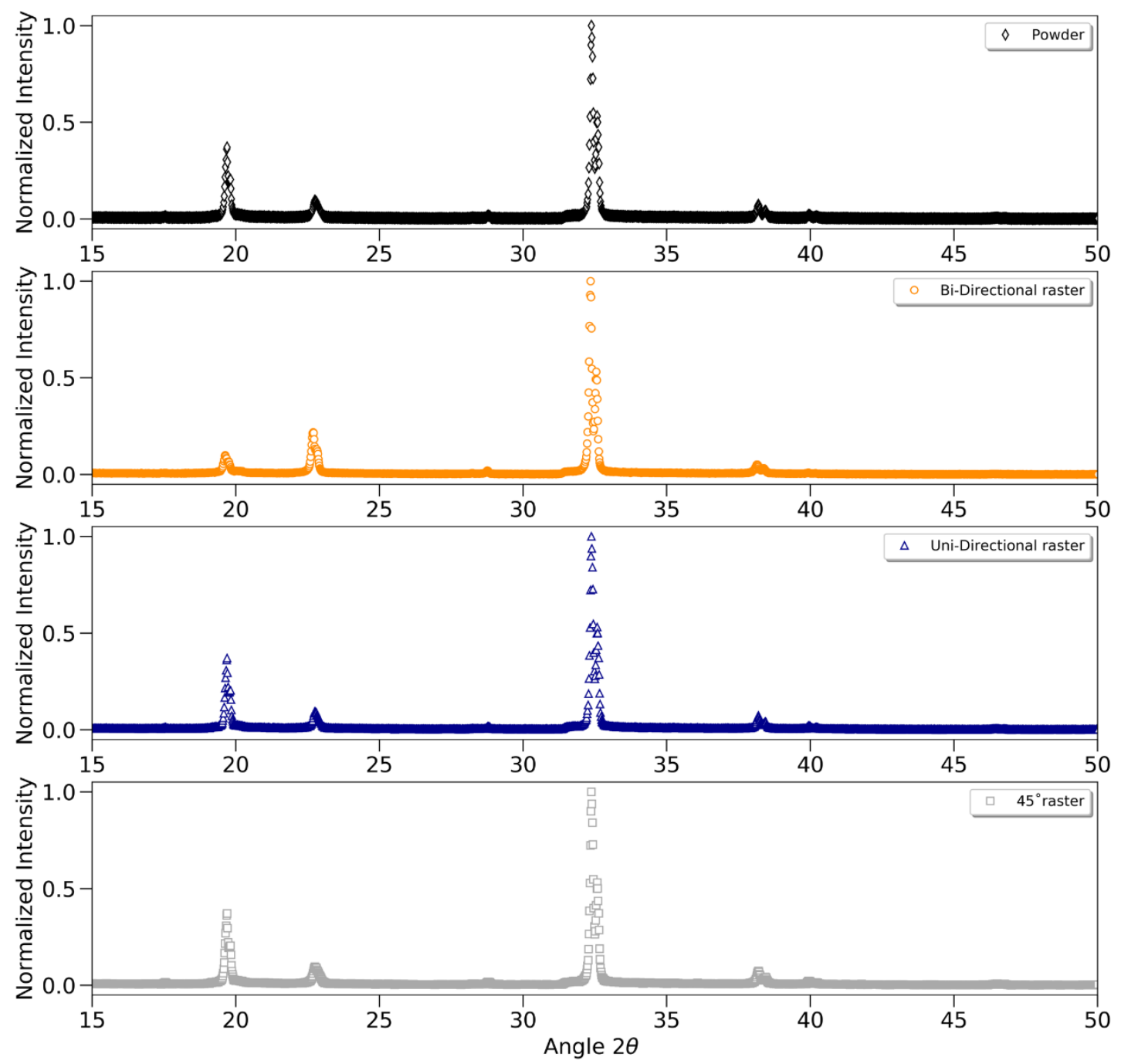
Figure 4. X-Ray diffraction results of the (a) Powder (b) Bidirectional raster (c) Uni directional raster (d) 45-degree raster. The X-Ray diffraction patterns shown the presence of $100 \%$ FCC phase in the builds

\section{Deposits fabricated with Composition-7:}

Composition 7 based on the CALPHAD calculations was designed to contain at least $8-10 \%$ FCC phase. The X-Ray diffraction analysis of the powder confirms this (Figure 6). The deposits were fabricated on a cast iron substrate using identical parameters used in the previous case. While in the previous case a total of 25 layers could be deposited in this case a total of 40 layers were deposited. The optical micrograph also shows limited cracking in the builds in the un etched condition. However, when the dimension of the build was reduced from 40X40X40 mm3 to 20X20X20 mm3 the cracking was eliminated (Figure 5). X-Ray diffraction did not indicate any phase differences in the microstructure between the two cases (Figure 6).
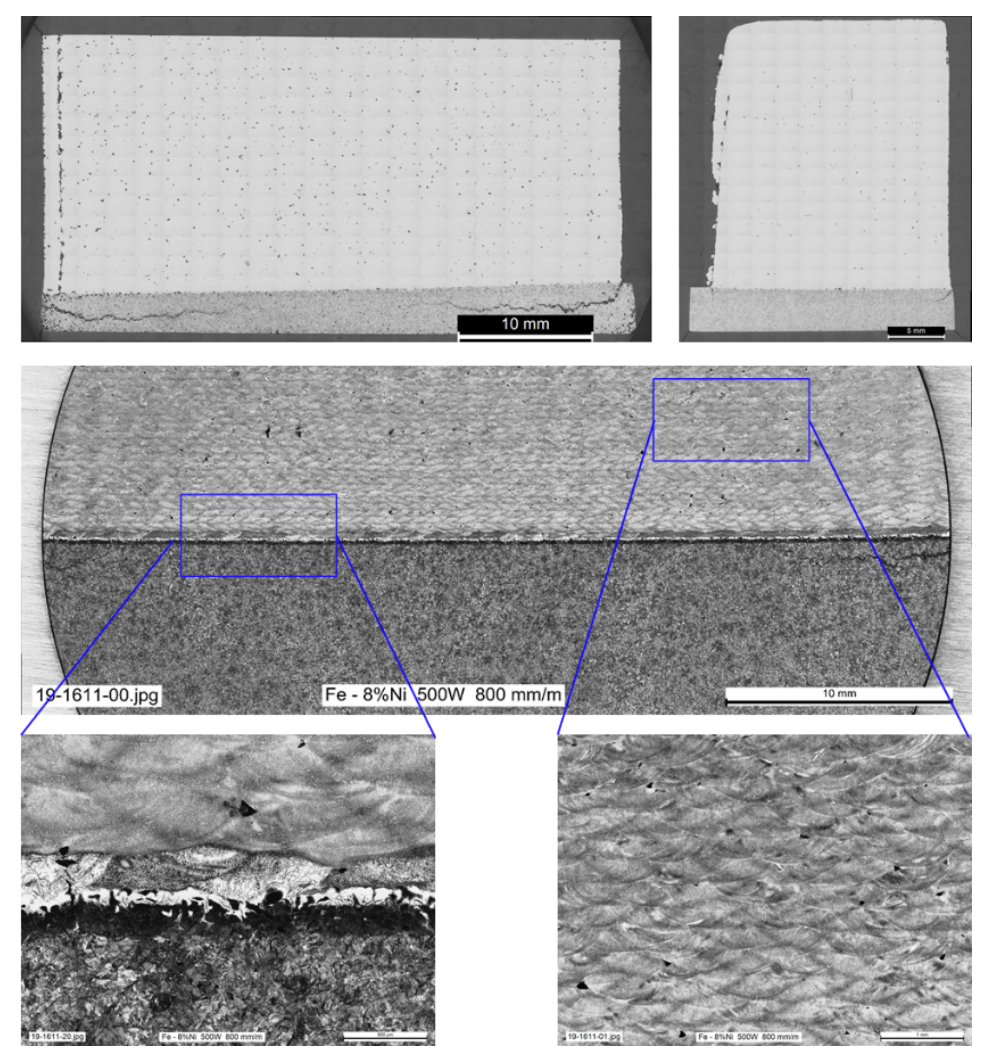

Figure 5. Optical micrograph (a) Un etched micrograph of the 40X40X40 mm3 samples showing cracks at the edges (b) $20 \times 20 \times 20 \mathrm{~mm} 33$ sample fabricated with identical process parameters (c) Etched microstructure of (a) (d) Interface at higher magnification (e) Micrograph of the deposit showing a martensitic structure 

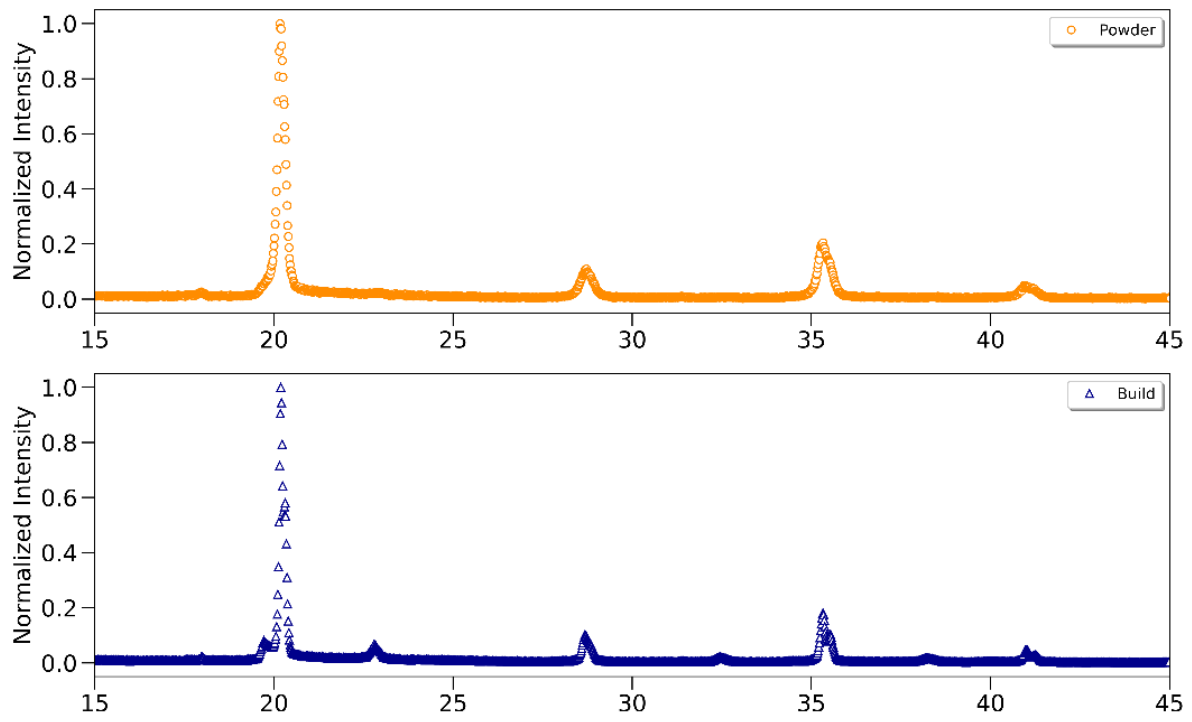

Figure 6. X-Ray diffraction of the powder and the build showing the presence of residual austenite films in the samples

\section{Deposits fabricated with Composition-3:}

Composition 3 had a higher alloy content, which reduced the martensite start temperature. Therefore, one would expect a lower cracking tendency in these builds. The exact same process parameters were used to fabricate the builds. The results demonstrate that a significant reduction in cracking along the edges was obtained. The results are summarized in Figure 7. The micrographs show that the lower transition temperature clearly reduced the cracking tendency in the builds while the smaller samples fabricated clearly showed the absence of any cracks. This could be attributed to the lower thermal mass in the smaller build which would lead to a higher average temperature during the build. This would lead to a slower cooling rate and therefore lower shrinkage strains thereby possibly reducing the cracking tendency. In addition, the fraction of retained austenite (RA) was also higher with $\sim 20 \%$ RA as measured using X-Ray diffraction (Figure 8). This should also help absorb some strain therefore lead to improved cracking resistance as shown in the previous studies, thus contributing to the increased cracking resistance. 


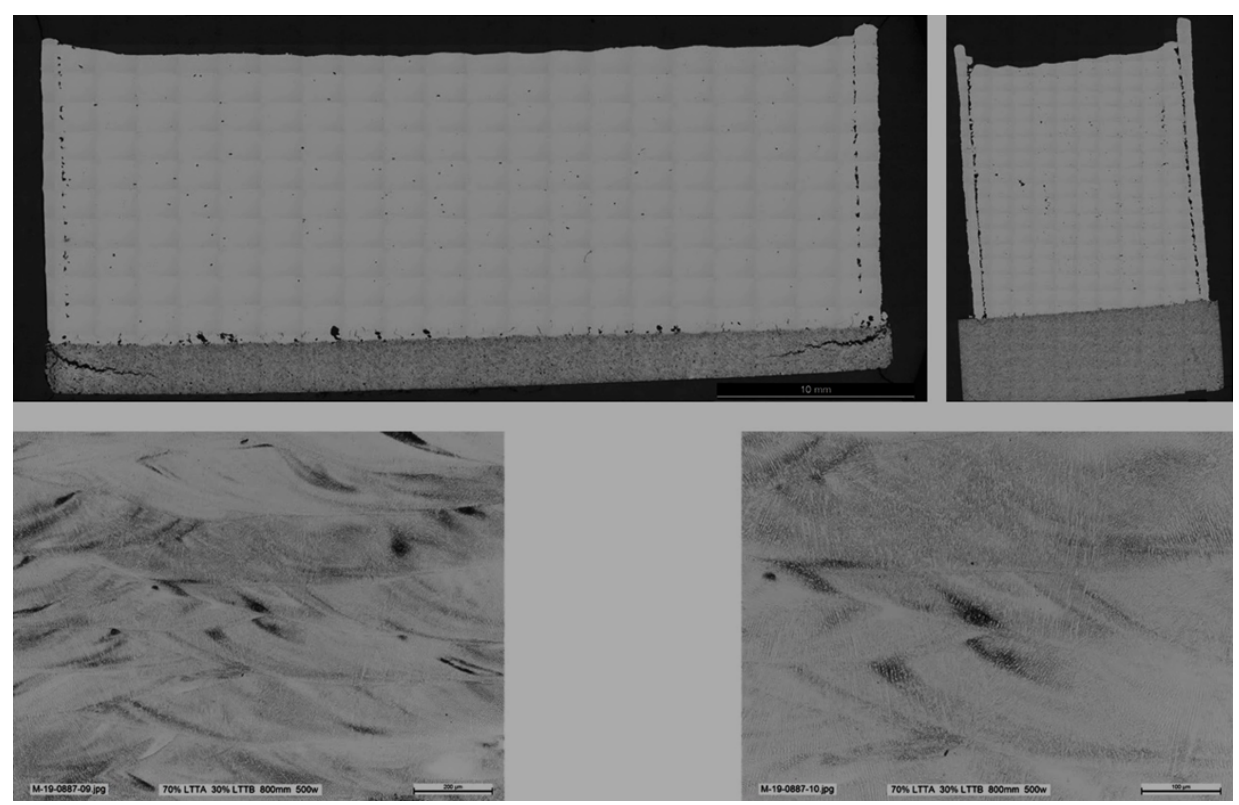

Figure 7. Optical micrographs of the (a) $40 \times 40 \times 40 \mathrm{~mm}^{3}$ sample in the un etched condition. Note that the cracks are smaller compared to the previous study (b) $20 \times 20 \times 20 \mathrm{~mm}^{3}$ sample in the un etched condition clearly showing the absence of cracking at the interface (kindly refer to figure 5 (b) (c) and (d) Etched micrographs of the samples showing the presence of martensite in the matrix with retained austenite in the inter dendritic area which is higher in alloying content

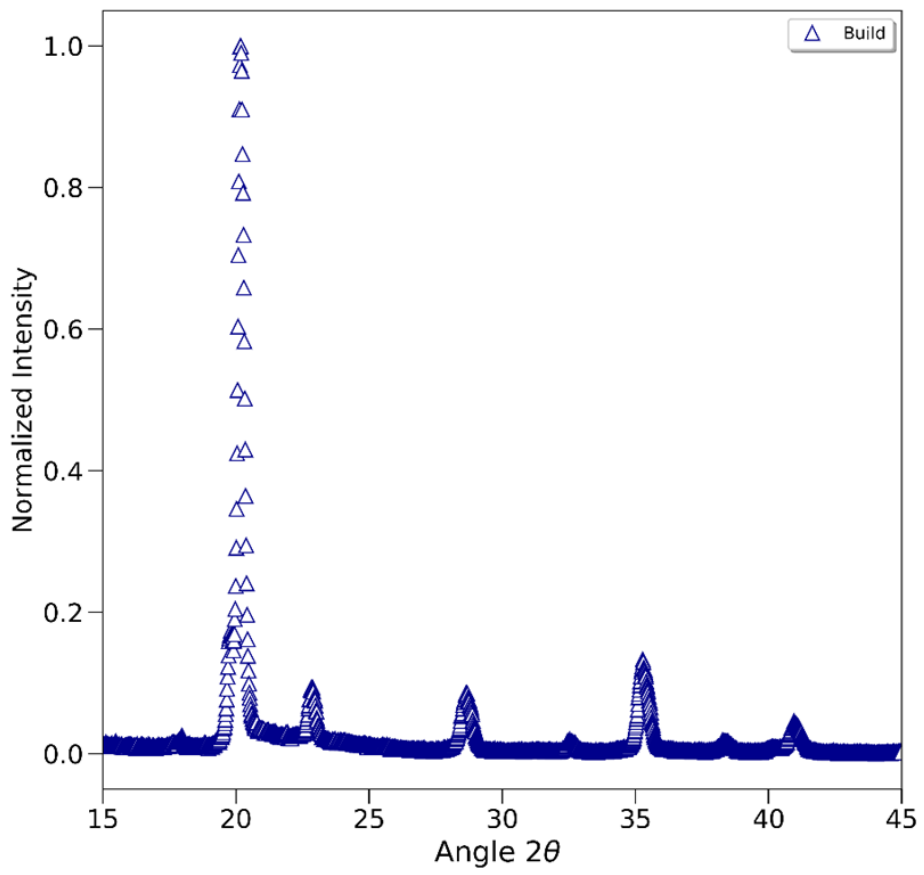

Figure 8. X-Ray diffraction the build showing the presence of residual austenite films in the samples 


\subsection{IMPACTS}

This work has demonstrated the potential of using the laser powder blown DMD system to develop solutions for repair applications and add new features on existing part. Though the laser powder blown process has been used extensively to rebuild worn turbine blades, the use of the technology for automotive applications and for difficult to weld materials, is novel. Remanufacturing of engine blocks would result in significant cost savings and also help in reducing the greenhouse gas emissions by up to $85 \%$.

\subsubsection{SUBJECT INVENTIONS}

N/A

\subsection{CONCLUSIONS}

In this Phase 2 study, two unique compositions of filler material were identified that resulted in significant reduction in cracking in the AM build as well as the cast iron substrate. It was demonstrated that the length of the AM builds i.e. the length of the interface also has an influence on the cracking tendency by showing that a reduction in the length of the build, cracking can be completely eliminated. A potential explanation for the geometric dependence of the cracking tendency is the change in thermal history during deposition. In a longer build, each point cools down to lower ambient temperature compared to a smaller geometry where the beam return time is faster thereby generally keeping the overall build at an elevated temperature and reducing the cooling rate to ambient temperature. In summary, a successful repair operation would rely on a combination of appropriate alloy selection for the filler material as well as being aware of the geometry effects. Thus, repairs requiring longer scan lengths can be divided into smaller sections to facilitate crack free deposition.

\section{CUMMINS, INC BACKGROUND}

Cummins Inc is a global power leader that designs, manufactures, sells and services diesel and alternative fuel engines from 2.8 to 95 liters, diesel and alternative-fueled electrical generator sets from 2.5 to 3,500 kW, as well as related components and technology. Cummins Inc serves its customers through its network of 600 company-owned and independent distributor facilities and more than 7,200 dealer locations in over 190 countries and territories. The Engine Segment manufactures and markets a complete line of diesel and natural gas-powered engines for on-highway and offhighway use. Its markets include heavy- and medium-duty truck and bus, light-duty automotive and off-highway (ranging from 60 to 755 horsepower). The Engine Segment also provides a full range of new parts and services and remanufactured parts and engines through an extensive distribution network.

\section{REFERENCES}

1. $\quad$ Handbook, A.S.M., Welding, brazing and soldering. ASM International, 1993. 6: p. 1187.

2. Handbook, W., MATERIALS AND APLICATIONS-PART 1.v. 3-. 1998, American Welding Society. Miami, Fl.

3. Ebrahimnia, M., et al., Effect of cooling rate and powder characteristics on the soundness of heat affected zone in powder welding of ductile cast iron. Materials \& Design, 2012. 33: p. 
551-556.

4. El-Banna, E.M., Effect of preheat on welding of ductile cast iron. Materials Letters, 1999. 41(1): p. 20-26.

5. Fernandes, F., et al., Effect of arc current on microstructure and wear characteristics of a Nibased coating deposited by PTA on gray cast iron. Surface and Coatings Technology, 2011. 205(16): p. 4094-4106.

6. $\quad$ Pouranvari, M., On the weldability of grey cast iron using nickel based filler metal. Materials \& Design, 2010. 31(7): p. 3253-3258.

7. Babu, S.S., et al., Toward prediction of microstructural evolution during laser surface alloying. Metallurgical and Materials transactions A, 2002. 33(4): p. 1189-1200. 